\title{
From the Inside Out: Effects of Parental Incarceration on Children
}

\author{
Deni Hanington ${ }^{1}$
}

\begin{abstract}
While incarceration rates have been increasing, conversations and knowledge on children with incarcerated parents have not. Children, like their parents, undergo challenges and serious adaptations when they lose their guardian to the criminal justice system. Studies done on children of incarcerated adults show the disproportionate impact on racialized and marginalized populations within Canada, as well as the economic consequences that follow. Due to various factors that unravel during these children's lives, they face more social risks than many other individuals developing at the same time under separate circumstances.
\end{abstract}

${ }^{1}$ MacEwan University 
Hanington

\section{Introduction}

Admittances of incarceration within North America have experienced a stark increase over the past number of years. These increases in incarceration have had the ability to create conversations, as well as studies, surrounding the topic of institutions and existing effects on inmates. Many inmates have families of their own, and children that are left without a parent when the individual becomes incarcerated. While incarceration rates have been increasing, conversations and knowledge on children with incarcerated parents have not. Children, like their parents, undergo challenges and serious adaptations when they lose their guardian to the criminal justice system. Studies done on children of incarcerated adults show the disproportionate impact on racialized and marginalized populations within Canada, as well as the economic consequences that follow (Knudsen, 2016, p. 18). Due to various factors that unravel during these children's lives, they face more social risks than many other individuals developing at the same time under separate circumstances. A study done by Correctional Service Canada extrapolated their research findings to determine that $4.6 \%$ of all children under the age of 19 in Canada have an incarcerated father (Correctional Service Canada, 2015). The Elizabeth Fry Society states that $66 \%$ of women in custody are mothers to children (Elizabeth Fry Society of Edmonton, 2018). These statistics demonstrate that children of incarcerated individuals are more common than our society is aware of. This systemic lack of awareness unknowingly reproduces the effects of stigma and shame. Youth with incarcerated parents have been referred to as "secondary victims of crime" as they may undergo changes in schools, family roles, different caretakers, economic distress and general feelings of shame or grief (Cunningham \& Baker, 2004, p. 2).

The goal of this paper is to examine the effects that parental incarceration has on children in various areas, and to what extent society can play a role in reversing them. Parental incarceration has the ability to cling to every facet of children's lives; effects can begin at birth, exist throughout development, and are visible in acts of deviance, feelings of grief and are able to create the existence of second generation offenders. Furthermore, youth who are Indigenous have become a statistic of overrepresentation and systemic racism within the criminal justice system, adding a layer of intersectionality to these challenges. Children visiting their parents in institutions have both successes and drawbacks that will be addressed. It is imperative to note areas in which society can help to reduce the negative effects of incarceration. Programs and services available to both inmates and children of incarcerated parents benefit from the potential to reduce adverse effects.

\section{Effects of Indigenous Overrepresentation}

Historically, Indigenous populations have been overrepresented within the criminal justice system of Canada due largely to no fault of their own. The colonization and systemic racism that Canadian Indigenous populations experience and endure are passed down generationally, producing multiple consequences through intergenerational trauma. The history of colonization of Indigenous individuals by the Canadian government requires that they maintain data on their population, including within the criminal justice system (Reasons et al., 2016, p. 78). The justice system has been directed to address the factors of overrepresentation during sentencing, which nonetheless have not lowered their rates within institutions (Manning, 2018, p. 6). Between 2016- 
2017, Indigenous individuals accounted for approximately $28 \%$ of admissions into Canadian correctional services while representing $4.1 \%$ of the adult Canadian population (Statistics Canada, 2018). To frame this in a more specific way, Saskatchewan's population is $14 \%$ Indigenous, yet $76 \%$ of custody admissions were from the same population (Statistics Canada, 2018). Manning (2018) notes that victimization influences how Indigenous populations are criminalized in Canada, especially when concerning the treatment of youth. Manning (2018) offers the high number of Indigenous youth within the Canadian foster care system as an example (p. 11). Intergenerational trauma creates cycles of abuse which often lead to criminal involvement. This institutional racism and systemic bias embed social control and assimilation within the criminal justice system.

Although Indigenous men are indeed notably overrepresented within the criminal justice system, women experience strikingly more oppression within the same environment. Indigenous women experience an additional factor of intersectionality compared to men within the same population, which adds to their overrepresentation within the criminal justice system. It is necessary to bring attention to the fact that Indigenous females account for an even larger proportion of the incarcerated population than did men, at $43 \%$ compared to $28 \%$ for males (Statistics Canada, 2018). Their augmented overrepresentation can be seen as a result of facing intersecting barriers of both racism and sexism (Manning, 2018, p. 41). Female youth who are Indigenous match these findings by accounting for a higher representation than their male counterparts as well. The Elizabeth Fry Society of Edmonton notes that the societal subordination experienced by Indigenous women produces internalized oppression (Elizabeth Fry Society of Edmonton, 2018). It should be noted that children who are from a marginalized population have a greater risk of experiencing the adverse effects of their parent's incarceration (Manning, 2018, p. $15)$.

The systemic discrimination that is institutionalized by the criminal justice system of Canada can be noted statistically year by year. The overrepresentation of marginalized and racialized individuals does not decrease overtime and is proof of the racial bias that exists within this dominant discourse. This affects the Indigenous population as a whole, as well as contributes to the barriers that stand in front of Indigenous youth generation by generation.

\section{Deviance and Delinquency}

A noted adverse effect of parental incarceration on children is the increase in general problem behaviours leading to deviancy. Youth with incarcerated parents grow up with the likelihood of increased delinquency due to factors surrounding their unique situation. A study done by Murray et al. (2012) determined that adolescent boys with incarcerated parents show higher levels of theft than those whose parents were not incarcerated (Murray, Loeber \& Pardini, 2012, p. 273). It is likely that stigma, as well as labelling, are important factors in the development of problem behaviours. Societal expectations surrounding incarcerated parents could cause children to adopt these behaviours into their own identity. Interestingly, the boys' levels of depression and academic performance were still similar to those of boys with no parental criminal justice involvement at all. The authors noted that this could be because of children's ability to show resilience in times of adversity (Murray, Loeber \& Pardini, 2012, p. 283). Resiliency could be engaged in through extra-curricular activities, positive peer relations, or general support from external sources. 
Losing a parent to the criminal justice system can also produce negative effects on attitude. Children who are exposed to parental incarceration are more likely to exhibit negative externalized behaviour by looking for attention in ways that are destructive (Turney \& Goodsell, 2018, p. 151). This behaviour could be a result of the increasing responsibilities that children are expected to handle during the absence of a parent, or because of their difficulty coming to terms with such a mature issue.

A valid concern regarding deviance comes from caregivers becoming worried that their children would be stereotyped as a criminal like their parents or discriminated against (Knudsen, 2016, p. 185). This occurs because youth face negative stigmatization as the child of an inmate, which can create rationalization of their parent's behaviours. Rationalization and normalization are a form of coping that can take the form of deviant actions like substance use, thrill seeking, and anger in order to suppress these emotions (Cunningham \& Baker, 2004, p. 6). While these coping strategies can be helpful in terms of distraction short-term, their long-term effects would likely have negative outcomes within their lives.

While youth mature and develop, their primary socialization begins through their parents. However, with aging comes a stronger association with peer groups which can take over parent's former social roles. Once peer groups start to emerge, fitting in and creating a good impression is paramount. The differences that having an incarcerated parent can cause affect youth in adverse ways. They may feel shame or embarrassment around the stigma that they carry (Cunningham \& Baker, 2013, p. 40). Moreover, they have lost the individual that they may have confided in while growing up. This socialization with peer groups can result in gang involvement of children due to their difficulty forming positive personal relationships (Elizabeth Fry Society of Greater Vancouver, 2005, p. 5). Parental incarceration can create adversity, vulnerability and added marginalization to children, creating a chain effect leading to problem behaviours and acts of deviance. These studies show that incarceration of one, or both, parents have overall harmful consequences for children's behaviour that will likely result in delinquency.

\section{Effects on Infants}

Within the first few years after birth, proper development is critical and will impact how one matures and grows for the rest of their life. This time is also key for forming healthy attachment styles with parents. Bowlby (1990) defines a secure base of attachment as being available for comfort, nourishment, and reassurance (p. 13). Therefore, attachment behaviour can be altered by pain, being frightened and inaccessibility to parents (Bowlby, 1990, p. 8). Infants with incarcerated parents lack stability within their homes, which compromises their ability to develop normally (Cunningham \& Baker, 2013, p. 28). They are also at elevated risk of criminal activity if they undergo multiple disruptions in attachment, increased stress and compromised self-regulation. Infants do not have as many internal support mechanisms as adults, which negatively affects their resiliency. Cunningham \& Baker (2004) found that $85 \%$ of infants with incarcerated mothers had been around intimate partner violence (p. 4). Moreover, younger children are more dependent on stable and affectionate relationships, thus leaving them more vulnerable to the adverse effects of parental incarceration. Poehlmann (2005) found that $63 \%$ of children had insecure relationships with their caregivers post parental incarceration (p. 690). Approximately two-thirds of infants 
within this study showed attachment relationships characterized by "intense ambivalence, disorganization, violence, or detachment" (Poehlmann, 2005, p. 690). As the baseline for relationship attachments occur within infancy, these standards of relationships could be carried into adulthood, producing negative bonding later on in life. These studies show that parental incarceration occurring earlier on in infancy has the ability to severely affect our most vulnerable population--those with the least amount of internal coping mechanisms in place.

Parental incarceration, unfortunately, carries the serious implications of correlating with increased infant mortality. It has been argued that incarceration reduces acts of homicide, however, it raises the occurrences of infant mortality (Light \& Marshall, 2015, p. 23). The study done by Light \& Marshall (2015) concluded that the rate of infant mortality would be $19 \%$ lower without incarceration. Within the period of their study there were 250,000 fewer homicides due to incarceration, yet approximately 203, 479 infant deaths (Light \& Marshall, 2015, p. 23). In essence, incarceration of those who are parents has resulted in lower survival rates for a population that is left vulnerable and entirely dependent on adults.

In addition, the effects of parental incarceration on infants can be carried into adulthood through adverse childhood experiences (ACEs). Dallaire et al. describe ACEs as traumatic experiences that occur during childhood, including the incarceration of a parent (Dallaire, Woodards, \& Kelsey, 2018, p. 83). Their study concluded that women who were affected by incarceration personally or through their partner were more likely to consume alcohol and smoke during pregnancy, and less likely to breastfeed (Dallaire, Woodards, \& Kelsey, 2018, p. 86). This results in lower birth rates and noted lower health outcomes throughout adulthood.

Infancy is a critical point of development, and as such parental incarceration affects the fragility of proper development in various ways. Incarceration affects infant attachment styles negatively, which can produce outcomes such as ambivalence, violence and insecurity. Parental incarceration has been shown to correlate with increased rates of infant mortality and is a marker for ACEs. A population as fragile as infants should not be open to the risk of detrimental effects on development that can come from incarceration. These consequences are serious, and as studies have shown, are carried throughout individual's lives.

\section{Grief}

Parents who are incarcerated, or have been in and out of the justice system, are not capable of being ever-present within the lives of their children. This relationship can differ between families as some parents may maintain contact or visits more than others. However, all children with incarcerated parents are experiencing a loss, whether this is simply the loss of a parent in the home or the residual effects that come from this. As with any form of grieving, loss and sadness can feel different for everyone, and come across in different ways. Boss (2016) describes ambiguous loss as either physical or psychological. Physical loss can be understood as not knowing if the individual in question is alive or not, yet they may still be psychologically present (p. 270). Psychological loss is counter to physical loss, in that the individual is present yet not psychologically available. In the context of parental incarceration, if a parent is physically absent yet psychologically present they are maintaining contact by sending letters, having phone calls or visits. Psychologically absent parents may have been released from an institution but do not seem 
the same as they were before their admittance. Ambiguous loss assumes a relationship of attachment to the person who is gone from an individual's life (Boss, 2016, p. 271). A study done in the United States concluded that their sample group of children experienced higher levels of stress as well as trauma in relation to the ambiguous loss of their incarcerated parent (Bocknek, Sanderson, \& Britner, 2009, p. 330). These children tended to be more hyper-vigilant and typically internalized their emotions. According to Bockneck et al. (2009) "ineffective coping is a hallmark symptom of both post-traumatic stress and ambiguous loss, serving as a link between trauma and symptomology" (p. 330). These children haven't developed proper coping which further effects other aspects of their lives, ranging from relationships with peers to properly channelling emotions.

Knudsen (2016) describes three non-mutually exclusive categories to children's loss. Firstly, children noted the secondary results of losses due to their parent's incarceration that was tangible or instrumental in their daily lives, such as playing or cooking. The next noted category was the lack of parents' ability to show their support, care or time while institutionalized. Thirdly, children simply missed having their parent around and the ability to see them (Knudsen, 2016, p. 138). A common theme throughout research is the inability for children to contextualize their grief over the loss of their parent due to ambiguity. The existence of support programs for children aiming to help define and lessen their grief could have a positive impact on their well-being, as well as the existing relationship they have with their parents. Additionally, grief education is something that could benefit both inmates as well as their children as it would help to quantify that feeling of loss.

\section{Second Generation Offenders}

Trauma as a result of distressing experiences has the ability to transcend through generations of family, continuing to affect each new generation. Second generation offenders are individuals who had, or have, a parent or caretaker who has also been incarcerated. A study done by Novero et al. (2011) showed that second generation offenders had higher instances of childhood adversities when compared to first generation offenders. Most notably, those whose parents were previously incarcerated experienced more than double the amount of parental substance abuse than previous first generation offenders (Novero, Loper, \& Warren, 2011, p. 770). They also had poorer levels of prison adjustment, higher instances of violation within prison, and increased cognitive and behavioural issues in terms of anger (Novero, Loper, \& Warren, 2011, p. 770-771). This study notes the unique impact that parental incarceration has on an individual's children, including the potential to exacerbate existing adversities within children's lives thus continuing the cycle of incarceration.

In order to compare rates of juvenile criminal activity between first and second generation offenders, Will et al. (2014) conducted a study that found second generation offenders more than doubled rates of violent, nonviolent and drug related activity as well as stints of juvenile detention (p. 200). These findings were more noticeable in males than in females. Interestingly, this study also noted that with increased experiences of childhood adversities came increased markers for conduct disorders (Will, Whalen, \& Loper, 2014, p. 205). The findings of this study imply that coping strategies are not properly formed within second generation offenders, beginning at a young 
age, as they engage in conduct disorder behaviours during their youth. Early emancipation from parental supervision, especially for adolescents, is one factor that contributes to higher rates of second generation offenders (Cunningham \& Baker, 2013, p. 42). With parents in jail, it is easier for individuals to rationalize their own behaviour in relation to that of their mother or father. Normalizing criminal behaviour with the added factor of emancipation develops pre-disposed opinions on their behaviours.

The incarceration of youth has also been shown to carry negative relations in other areas of life. A study conducted in Vancouver, Canada on street-involved youth who have used illicit drugs found that incarceration was positively associated with a relapse into stimulants and opioid use (Goldman-Hasbun, Nosova, Kerr, Wood, \& DeBeck, 2019, p. 432). Out of the 32 participants that had been incarcerated, 23 had relapsed into substance abuse. This study was able to draw attention to the relationship that exists between substance abuse and trauma, which are experienced by second generation offenders. The authors note that relying on the criminal justice system to address substance abuse may do more harm than good as together they are often part of a vicious cycle.

Effects on others in relation to an individual's incarceration are generally not topics of study within the criminal justice system. The neglect of systematic research on parental incarceration ignores the possibility that detrimental effects exist for children. With this in mind, Hagan \& Dinovitzer (1999) state that the impact on each new generation is potentially the least understood consequence of incarceration (p. 153). This can be referred to as a "bubble effect" in which increasingly more children grow up with incarcerated parents end up in the justice system due to these generational patterns (Will, Whalen, \& Loper, 2014, p. 207). In consideration of the bubble effect, it can be assumed that we will continue to watch populations of inmates rise. Without intervention through research this cycle will continue, costing both society as well as future generations stemming from inmates.

\section{Visitation}

Options of contact for children of incarcerated parents are typically limited to letters, phone calls, and depending on individual institutions, visitations. Variables affecting the ability to visit are both internal and external. Visitation programs differ between federal and provincial institutions, can depend on the charge of the individual, as well as how the program is conducted by each institution. Externally, visitation isn't always a possibility for those who do not live near where their parent is incarcerated, may not be available if they lack a caregiver to bring them, and in some cases will not be allowed entry without proper identification. Visitation can carry benefits for both children of inmates as well as the inmates themselves. In an evaluation of a Canadian penitentiary visitation program, inmates saw visits as a way to distance themselves from prison life (Duncan \& Balbar, 2008, p. 311). Inmates noted the importance of being able to talk to those outside in order to rid feelings of loneliness and frustration, and to feel like a person rather than a criminal. In terms of benefitting inmates' futures, visitation engendered feelings of hope and motivation while increasing their self-esteem, all beneficial factors for those that are also parents (Duncan \& Balbar, 2008, p. 312). 
Successes and drawbacks of visiting programs may also depend on how visits are able to be conducted. For example, research based in the states finds that no contact during visitation is normal for prisons, as the first point of entry for offenders, due to security concerns and a lack of emphasis on family needs (Arditti, 2003, p. 132). Canada's provincial institutions are typically run with these same regulations as most provincial and remand settings are closed visits, meaning through glass (John Howard Society of Ontario, 2014, p. 7). Provincial prisons generally have shorter times for visitation than federal prisons as federal visits are typically open and allow individuals contact with their visitors (John Howard Society of Ontario, 2014, p. 7). Limitations of visits serve as gate-keeping for the correctional system (Arditti, 2003, p. 132). These visits provide connection while simultaneously emphasizing the separation of loved ones.

Unfortunately, there are many potential drawbacks to children visiting their parent in an institution. Children must undergo the same security measures as all other visitors, meaning they will likely go through detectors and ion scanners, and could be introduced to drug dogs. The John Howard Society notes that it might be shocking for children to see their parents in uniform and highlights the importance of talking to them about how they're feeling afterwards (John Howard Society of Ontario, 2014, p. 13). Most notable may be the inconsistencies between federal and provincial institutions from the perspective of children's individual rights. There are noted differences in Canadian provincial and federal prisons are stark, with provincial prisons carrying an unfriendly environment for children with no evidence of efforts to promote a positive experience (Knudsen, 2011, p. 2).

Knowledge of Canadian visitation programs is limited as the bulk of research conducted within North American institutions comes from the United States. Within Canada, no consistent reports are kept on inmates who are parents, the age of children, or information on who is caring for those of the incarcerated parent (Knudsen, 2011, p. 6). In a separate study on experiences of Canadian children of incarcerated individuals, Knudsen notes that while children enjoy the opportunity to see their parents, these visits fail to note the needs of children (Knudsen, 2014, p. 195). If visitation programs focus mainly on rehabilitation of the incarcerated, the development and coping skills of children may be unintentionally placed on the back burner. In order to improve the current situation of children with incarcerated parents, they first require the attention they deserve alongside additional programs and support.

\section{Reduction of Adverse Effects}

Although what research exists on children of incarcerated individuals focuses on the detrimental effects that can develop, these effects have identified room for improvement with consideration to the development of children within the criminal justice system. Change within institutions, as well as external services, are critical to reduce adversities experienced by children.

One of the larger strategies, requiring an upheaval of the way the criminal justice system currently functions, is utilizing alternatives to incarceration. Using community-based alternatives would benefit both offenders and children by being able to keep families intact without breaking down the existence of any social supports (Cunningham \& Baker, 2004, , p. 7). The Elizabeth Fry Society of Edmonton compares the cost of incarceration for women to the cost of social work employment and single living in Canada. They determined that one woman could have the care of 
four full-time social workers, as well as paid living expenses, for the same cost as incarceration within Canada (Elizabeth Fry Society of Edmonton, 2018). There is a large amount of evidence that suggests incarceration rates could be reduced without affecting the safety of communities (Knudsen, 2016, p. 269). Taking into account the parental status of offenders during sentencing in order to avoid incarceration leaves room for the possibility of positive affects on the development of children, in turn reducing future rates of incarceration and recidivism. Simply put, as parental incarceration imposes risks on children, a key response would be to reduce unnecessary imprisonment of parents (Knudsen, 2016, p.269).

There are many small acts that anyone can do that will help reduce risks associated with parental incarceration. One can begin by simply accepting children without stigma or labels, and treating them with the respect that all people deserve. Everyone can help children who may be deprived of the things their parents did for them by offering support; whether that means providing healthy foods, community resources, or starting food/toy banks for children in your own community. Helping children feel like children can be a simple task, but it might be the closest thing to normalcy that they've felt in a long time, and that can truly make all the difference.

Additionally, many studies have called for supportive programs to be put in place for both parents and their children. A Canadian study found no evidence of children of incarcerated individuals being the subject of attention, programming or services (Knudsen, 2016, p. 240). Knudsen (2016) argues that this absence contradicts child poverty goals as children are absent from the social and prison policies that affect them (p. 254). These children live in adversity, but are seemingly invisible to those that can make the largest difference for them. Turney \& Goodsell (2018) note that three areas require particular focus in order to reduce childhood inequalities: strengthening parental relationships, increasing economic wellbeing, and treating substance abuse (p. 157). There is a call to create programs for incarcerated parents that operate more externally, rather than placing them in a vacuum (Turney \& Goodsell, 2018, p. 160). These supportive programs aid children by developing resiliency as well as reducing stigma. Programs can also help lower deprivation of proper nutrition and housing by conducting food and clothing drives and offering families additional resources (Elizabeth Fry Society of Greater Vancouver, 2019, p. 9). Programs that work with children throughout their parent's incarceration would have the ability to curve adverse developmental effects before they become a concrete aspect of their lives.

Additionally, there have been calls to action to plan for meaningful release in terms of setting up incarcerated individuals for success. Cunningham \& Baker (2004) suggest to plan for release by securing a place to live, creating a strategy to find a job and applying to treatment (p. 9). A release plan would take the place of dropping offenders off at a halfway house with no external forms of support set up previously. Avoiding re-involvement with the criminal justice system, as well as lowering chances of recidivism, is definitively the best way to help children of incarcerated parents (Cunningham \& Baker, 2004, p. 9).

In turn, adopting these changes in society will reduce the cycle of second generation offenders, as well as the potential to curb the chance of re-offending within existing inmates. Proper support and coping strategies would further benefit children as they develop. Ultimately, the costs of not facilitating programs and support for children of incarcerated parents are much worse than those that come from helping. 
Hanington

\section{Conclusion}

The incarceration of parents can have effects on their children in many diverse ways. As the administration of offenders into institutions continues to increase, so too will the effects on their children. There is a high percentage of children within society who live without one, or both, of their parents due to the way the Canadian criminal justice system operates. The percentages are even higher for children of Indigenous populations, as their mothers and fathers face frightening overrepresentation due to systematic biases of racism and sexism. These children will live with a stigma that may develop into behavioural problems, issues of theft, and difficulty forming positive relationships. Infants who experience this trauma will likely form negative attachment styles with others and experience lower health outcomes throughout their adult life. Losing a parent to the system can impact the way children cope with grief as they experience the ambiguity of incarceration. Parental incarceration is part of a cycle that produces second generation offenders, who experience more serious adverse effects than their parents. Although visitation with parents may provide comfort, they can be confusing and frightening for children to experience. Lastly, with all the risks accompanied by parental incarceration, there exists suggestions to reduce these outcomes on children. Studies have suggested lowering rates of incarceration for parents, facilitating programs for all individuals involved, and creating a solid release plan to reduce the chance of re-offending.

This paper has highlighted the lack of Canadian research on incarceration, as well as the need for more research and collection of data on the children of inmates. It is clear that children experience life differently due to their parent's incarceration. There is only so much that can be done to reduce the adverse effects of incarceration on children with the lack of knowledge that is currently available. Canada would benefit from more research being done on incarceration within our country. In order to begin making changes in society, future research should focus on children of those incarcerated. Additional research would spread awareness of the vulnerable population of children that rely on adults to do the best they can for them. 


\section{References}

Arditti, J. A. (2003). Locked Doors and Glass Walls: Family Visiting at a Local Jail. Journal of Loss and Trauma, 8(2), 115-138. doi:10.1080/15325020305864

Bocknek, E. L., Sanderson, J., \& Britner, P. A. (2009). Ambiguous Loss and Post-traumatic Stress in School-Age Children of Prisoners. Journal of Child and Family Studies, 18, 323-333. doi:10.1007/s10826-008-9233-y

Boss, P. (2016). The Context and Process of Theory Development: The Story of Ambiguous Loss. Journal of Family Theory \& Review, 8(3), 269-286. doi:10.1111/jftr.12152

Bowlby, J. (1990). A Secure Base: Parent-Child Attachment and Healthy Human Development. New York: Basic Books.

Correctional Service Canada. (2015, March 5). Incarcerated Fathers: A Descriptive Analysis. Retrieved from https://www.csc-scc.gc.ca/research/r186eng.shtml\#number-incar

Cunningham, A. and Baker L. (2004). 'Invisible Victims: The Children of Women in Prison.” Voices for Children. Retrieved from http://www.voicesforchildren.ca/ on November 19, 2019.

Cunningham, A. \& Baker, L. (2013). Waiting for Mommy. [electronic resource]: Giving a Voice to the Hidden Victims of Imprisonment. Centre for Children and Families in the Justice Systems. Retrieved from https://www.deslibris.ca/ID/236228 on November 19th, 2019.

Dallaire, D., Woodards, A., \& Kelsey, C. (2018). Impact of Parental Incarceration on Neo-natal Outcomes and Newborn Home Environments: A Case-Control Study. Public Health, 165, 82-87. doi:10.1016/j.puhe.2018.08.008

Duncan, H. E., \& Balbar, S. (2008). Evaluation of a Visitation Program at a Canadian Penitentiary. The Prison Journal, 88(2), 300-327. doi:10.1177/0032885508319210

Elizabeth Fry Society of Edmonton. (2018). Other Resources. Retrieved from https:// https://www.efryedmonton.ab.ca/ on November 12th, 2019

Elizabeth Fry Society of Greater Vancouver. (2019). Supporting Children with Incarcerated Parents. Retrieved from https://elizabethfry.com/we-can-help/ resources/ on November 2nd, 2019

Goldman-Hasbun, J., Nosova, E., Kerr, T., Wood, E., \& DeBeck, K. (2019). Homelessness and Incarceration Associated with Relapse into Stimulant Opiod Use among Youth who are Street-involved in Vancouver, Canada. Drug and Alcohol Review, 38(4), 428-434. doi:10.1111/dar.12921

Hagan, J., \& Dinovitzer, R. (1999). Collateral Consequences of Imprisonment for Children, Communities, and Prisoners. Crime and Justice, 26, 121-162. doi:10.1086/449296

John Howard Society of Ontario. (2014, July 24). Visiting a Loved One Inside? A Handbook for People Visiting a Prisoner at an Adult Correctional Facility in Ontario. Retrieved from https://johnhoward.on.ca/resources/visiting-loved-ones/ on November 24th, 2019

Knudsen, E. M. (2011). Submission to the UN Committee on the Rights of the Child 2011 Day of General Discussion: "Children of incarcerated parents". Retrieved from https://www.ohchr.org/Documents/HRBodies/CRC/Discussions/2011/ Submissions/EKnudsenSubmission.pdf on November 18th, 2019 
Knudsen, E. M. (2016). The Experiences of Canadian Children of Prisoners (Master's thesis, London School of Economics and Political Science, London, England). Retrieved from http://etheses.lse.ac.uk/id/eprint/3501

Light, M., \& Marshall, J. (2015). How Many Lives Does Incarceration Actually Save? Accounting for Infant Mortality in the Incarceration Ledger. American Sociological Association, 1-39.

Manning, N. (2018). Exploring Indigenous Youth Incarceration in Canada (Doctoral dissertation, University of Guelph, Guelph, Canada). Retrieved from https:// atrium.lib.uoguelph.ca/xmlui/bitstream/handle/10214/13022/ Manning_ExploringIndigenousYouthIncarceration.pdfsequence $=3 \&$ is Allowed $=\mathrm{y}$

Murray, J., Loeber, R., \& Pardini, D. (2012). Parental Involvement in the Criminal Justice and the Development of Youth Theft, Marijuana Use, Depression and Poor Academic Performance. American Society of Criminology, 50(1), 255-302. doi:10.1111/j.1745-9125.2011.00257.x

Novero, C., Loper, A. B., \& Warren, J. (2011). Second-Generation Prisoners: Childhood Adversities for Inmates With a History of Parental Incarceration. Criminal Justice and Behaviour, 38(8), 761-778. doi:10.1177/0093854811406637

Poehlmann, J. (2005). Representations of Attachment Relationships in Children of Incarcerated Mothers. Child Development, 76(3), 679-696. doi:10.1111/ j.1467-8624.2005.00871.x

Reasons, C., Hassan, S., Ma, M., Monchalin, L., Bige, M., Paras, C., \& Arora, S. (2016). Race and Criminal Justice in Canada. International Journal of Criminal Justice Sciences, 11(2), 75-99.

Statistics Canada. (2018, June 19). Adult and youth correctional statistics in Canada, 2016/2017. Retrieved from https://www150.statcan.gc.ca/n1/pub/85-002-x/ 2018001/article/54972-eng.htm

Turney, K., \& Goodsell, R. (2018). Parental Incarceration and Children's Wellbeing. The Future of Children, 28(1), 147-164. doi:10.1353/foc.2018.0007

Will, J. L., Whalen, M. L., \& Loper, A. B. (2014). From One Generation to the Next: Childhood Experiences of Antisocial Behavior and Parental Incarceration Among Adult Inmates. Journal of Offender Rehabilitation, 53(3), 190-210. doi:10.1080/10509674.2014.887606 